Journal of Engineering and Applied Sciences 14 (18): 6723-6730, 2019

ISSN: 1816-949X

(C) Medwell Journals, 2019

\title{
Effect of Load Frequency on the Track Rail and Subgrade Layer Settlement
}

\author{
${ }^{1}$ Qutaiba G. Majeed, ${ }^{2}$ Mohammed Y. Fattah and ${ }^{2}$ Hassan H. Joni \\ ${ }^{1}$ Department of Civil Engineering, College of Engineering, Daiyla University, Daiyla, Iraq \\ ${ }^{2}$ Department of Building and Construction Engineering, University of Technology, Baghdad, Iraq \\ eng_qgm79@yahoo.com
}

\begin{abstract}
In this study, a full scale railway track model is d by Abaqus V6.14 program in order to implement a parametric study. Numerical simulation with 3D model adopted to simulate analysis to get the results. Thirty six cases models are investigated and simulated with include subgrade layer of 100,70 and $60 \%$ degree of saturation at load frequency $1,2,4,6,8$ and $10 \mathrm{~Hz}$ under two loaded amplitude 200 and $250 \mathrm{kN}$. The effect of degree saturation had established by entering the value of matric suction in the geostatic step followed by static step of soil procedure and then propagating its effect on the soil as stiffness to the next steps. The matric suction value, according to that will not be changed through the dynamic step and will be the same one that was entered as a predefined value at the initial stage. The values of strains are calculated reflecting the effect of matric suction on the stiffness of the soil without regarding to the matric suction change effect. It had been concluded that the increase of load frequency lead to increase in rate of track and this rate of increases are almost same for all degrees of saturation. While the increase of load frequency lead to increase in rate of subgrade settlement and this rate of increases was higher at the higher load amplitude and the lower degree of saturation.
\end{abstract}

Key words: Railway track, finite elements, cyclic loading, unsaturated soil, saturation, predefined

\section{INTRODUCTION}

The railway track framework assumes an imperative part in giving a decent transportation framework in a nation. An extensive part of the yearly spending plan to support the railway track framework goes into track upkeep. Previously, most consideration has been given to the track superstructure comprising of the rails, the clasp and the sleepers and less consideration has been given to the substructure comprising of the ballast, the subballast and the subgrade. Despite the fact that the substructure parts impact the expense of track support, less consideration has been given to the substructure on the grounds that the properties of the substructure are more factor and hard to define than those of the superstructure (Selig and Waters, 1994).

The subgrade soil layer characteristics are administered in the magnitude of stress that may be applied to the subgrade layer. Among all types of subgrade layer soil, the most popular problematic soil is the cohesive one (Otter, 2011). Subgrade soil is often unsaturated and subject to seasonal variations of moisture content and hence suction in the field (Jin et al., 1994; Khoury and Zaman, 2004). The cohesive soils are well known to be highly influenced by change of their water content which leads to change of its physical characteristics that affect the shear strength parameter and the stress-strain behavior. In the field, subgrade soil is frequently unsaturated and subjected to day by day varieties of water content (suction) and temperature (Jin et al., 1994; McCartney and Khosravi, 2012).

Many theoretical and experimental studies have shown that unsaturated soil behavior depends heavily on suction and temperature (Romero et al., 2003; Tang et al., 2008; Francois and Laloui, 2008; Uchaipichat and Khalili, 2009). Increase in strength and stiffness of the soil is likely to occur according to the value of the suction, (Vanapalli et al., 1998; Mancuso et al., 2002). It was found by Grabe (2003) that the stiffness obtained in the laboratory was lower than that back-calculated from field observation for saturated specimens replicating railway formation. The dynamic reaction of cohesive soils has been somewhat generally considered utilizing distinctive experimental procedures. These incorporate cyclic triaxial, cyclic direct simple shear, resonant column and bender element tests. The principle distinction between these tests is the strain magnitude to which a soil test is subjected. The loading conditions forced in a given cyclic test on a cohesive soil influence its reaction. Specifically, the cyclic reaction of such soils relies upon the frequency and kind of cyclic loading and additionally on the cyclic stress level (or cyclic strain magnitude). Cyclic loading is

Corresponding Author: Qutaiba G. Majeed, Department of Civil Engineering, College of Engineering, Daiyla University, Daiyla, Iraq, eng_qgm79@yahoo.com 
commonly applied by either stress-or strain-controlled conditions. In numerous past cyclic tests, the loading was utilized at frequencies extending somewhere in the range of 0.1 and $0.5 \mathrm{~Hz}$ (Nieto-Leal and Kaliakin, 2013).

The objective of the study is to simulate numerically the railway system and study the effect of load frequency on the settlement of railway and under line subgrade layer.

\section{MATERIALS AND METHODS}

Model and material properties: The ballast is assumed to follow a Drucker-Prager failure criterion. In order to enhance numerical stability and abstain from modeling challenges, for example, localization issues at or close sharp singularities, a little estimation of cohesion of $1 \mathrm{kPa}$ was doled out to the ballast as proposed by Leshchinsky and Ling (2013).

The sleepers used in the simulation are made of concrete. The sleepers are modeled as linear elastic as non-yielding behavior is expected for sleepers, according to, the high value of stiffness of sleeper in comparison to the ballast. Subgrade clay soil is modeled as a hardening undrained Mohr-Columb soil without considering any time-dependent behavior. Material properties used in the numerical analysis are listed in Table 1.

Railway substructure geometry: The concrete sleeper has a length of $2.75 \mathrm{~m}$ with a thickness of 0.18 and $0.20 \mathrm{~m}$ width. They are spaced at $0.65 \mathrm{~m}$ on center (Chandra and Agarwal, 2007). The ballast embankment base width is $4.8 \mathrm{~m}$, crest width is 4.0 and $0.4 \mathrm{~m}$ in height. The slopes have an inclination of $1: 1$ as specified by various rail design manuals (Leshchinsky and Ling, 2013; Chandra and Agarwal, 2007). Figure 1 shows the typical section of rail way. The ballast layer is placed on subgade clayey layer of $12 \mathrm{~m}$ for depth and $14 \mathrm{~m}$ for $\mathrm{X}$ and $\mathrm{Y}$ directions.

Finite element mesh and boundary conditions: The mesh consists of 2225 elements of hexahedron 8 node type (pore fluid/stress) for the subgrade layer material and (3D stress) for the sleeper and ballast material.

The surface to surface contact is considered as more accurate method to model the contact issue, hence, it was used in this numerical analysis simulation of this work. The master slave concept established during 1995 by Wriggers is adopted to simulate the ballast and sleepers contact and the interaction process

The tangential component of the contact behavior providing the transformation of the stresses between the attached surfaces and this relationship can be described by the frictional behavior. Additionally, the normal component which can represent the interpenetration of the attached bodies and the normal stiffness has been defined as hard contact.

Table 1: Material properties used in the numerical analysis

\begin{tabular}{llll}
\hline Parameter & Clay & Ballast & Sleeper(timber) \\
\hline Material model & Mohr-Coulomb & Drucker-Prager Linear elastic \\
Dry unit weight $\left(\mathrm{kN} / \mathrm{m}^{3}\right)$ & 19.50 & 17.83 & 9.00 \\
Modulus of elasticity & Variable & $110 \times 10^{3}$ & $7.2 \times 10^{6}$ \\
$\left(\mathrm{kN} / \mathrm{m}^{2}\right)$ & & & \\
Cohesion $(\mathrm{Cu})$ & Variable & 0 & - \\
Friction angle $(\phi)$ & 1 & $45^{\circ}$ & - \\
Dilatancy angle $(\Psi)$ & 1 & 15 & - \\
Poisson's ratio $(\mathrm{v})$ & 0.449 & 0.350 & 0.300 \\
Initial void ratio $\left(\mathrm{e}_{\text {initial }}\right)$ & 0.61 & 0.70 & - \\
\hline
\end{tabular}

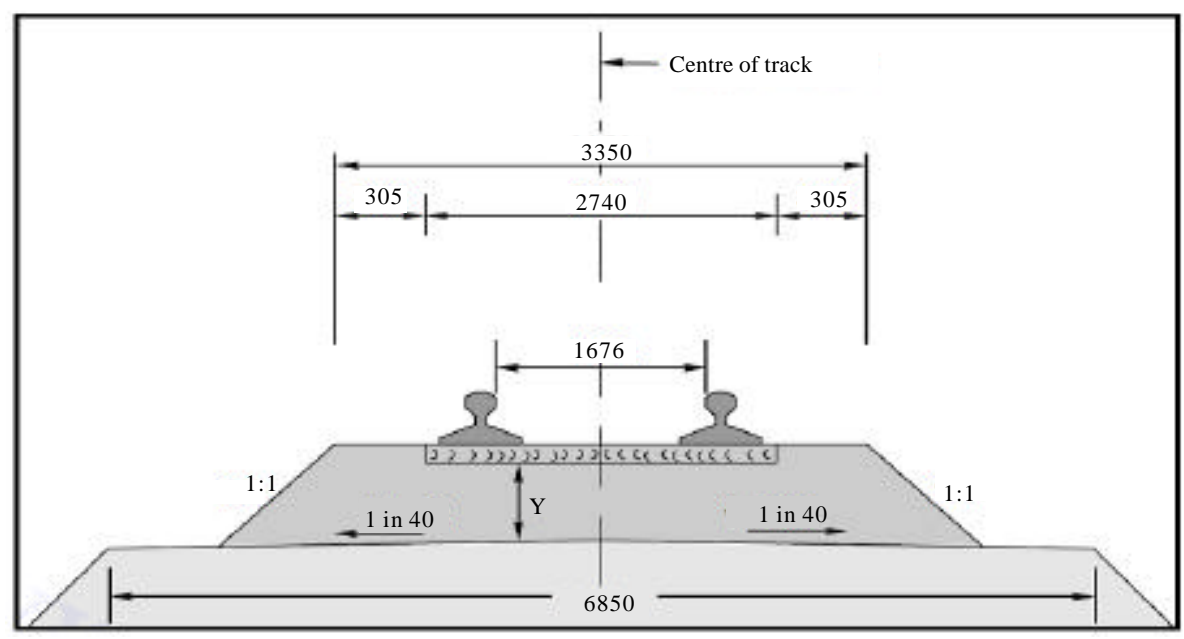

Fig. 1: Standard ballast profile for broad gauge (Chandra and Agarwal, 2007) 


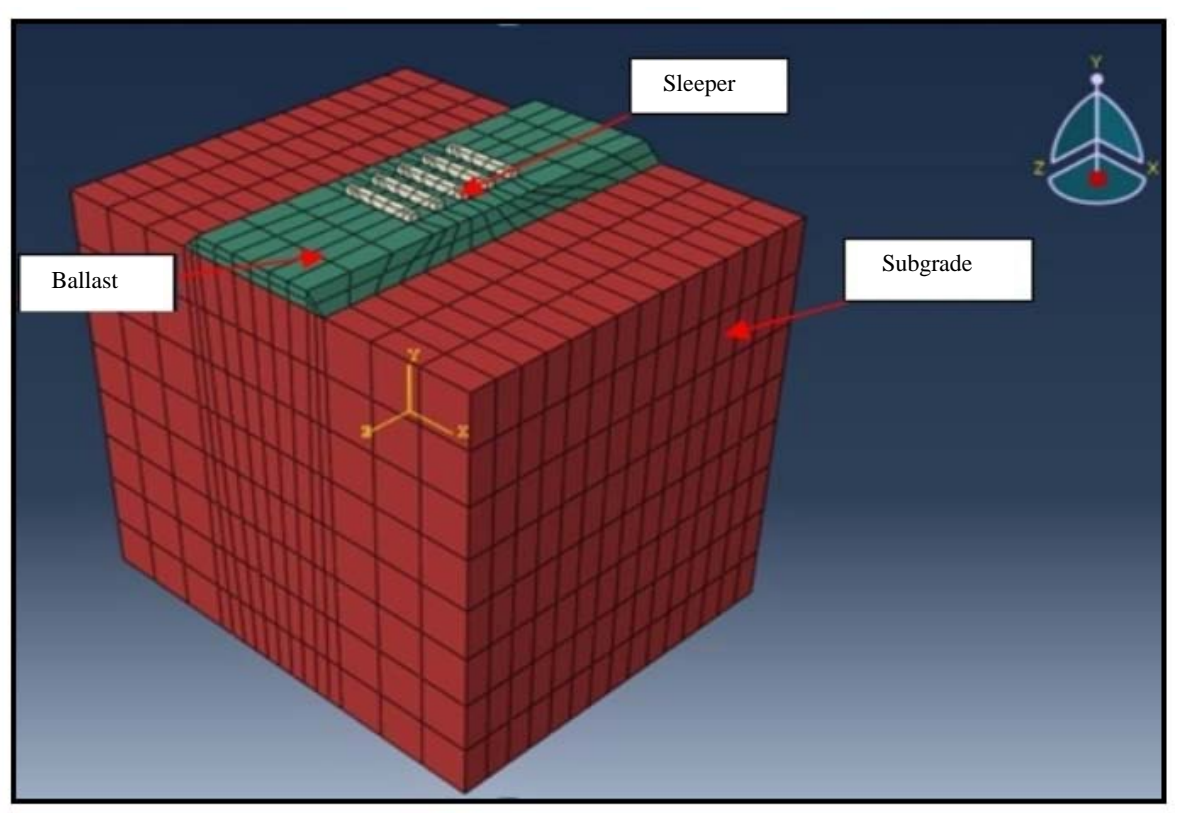

Fig. 2: Finite element mesh and parts assembly of full scale numerical analysis model

Absorbent boundaries were used in these models to reduce the wave reflection at the boundaries to avoid any possible fictitious ground wave reflections caused by dynamic loading that otherwise would be reflected inside the soil body mass. Figure 2 depicts the full scale model and finite element mesh used in the numerical analysis.

The typical passenger trains have a maximum axle load of 15-20 ton and heavy haul freight trains have a maximum axle load of 24-36 ton. Maximum axle load of an empty typical passenger train is 10 tonnes (Anonymous, 2011; Esveld, 2001; Grabe, 2003). Mainly, two general schemes of numerical integration for dynamic's problems are available, the implicit and the explicit algorithms. In the implicit procedure, matrix system is solved one or more time through one step to develop the solution.

The stability of the solution, besides the accuracy of the results of an efficient integration algorithm is always desired. Therefore, in current study, dynamic analysis is accomplished based on the dynamic implicit integration operator which is largely used in dynamic problems that contain nonlinearities due to its accuracy in the term of the mechanical behavior and more stability limits through time step. Displacements are evaluated throughout the rail substructure in order to investigate the effect of the parameters variations on strains behavior.

Loading: A full scale model with five sleepers cross section of rail track is adopted in performing this numerical analysis. Aload amplitude of 250 and $200 \mathrm{kN}$ is (a)
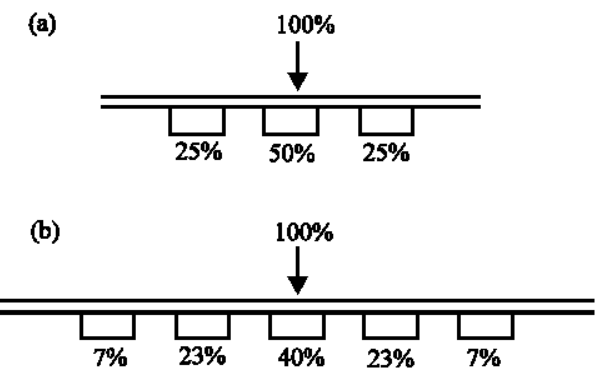

Fig. 3: Load distributions along successive sleepers: a) Suggested by Awoleye (1993) and used in this project and b) Profillidis (2000)

used in order to demonstrate the track loading behavior. The load is applied and distributed dynamically above the sleepers as shown in Fig. 3. When determining cyclic loading, it is also important to characterize the shape and duration of loading pulses applied to the ballast and subgrade materials. Two types of stress pulses are often used in a repeated load test. They are the haversine pulse and the trapezoidal pulse.

A study by Li (1994) suggested that the loading pulse by a single axle can be approximately represented by a haversine pulse for the track and subgrade (Fattah et al., 2017). However, for the two axles under the same truck or four axles under two adjacent trucks, loading pulse shape is more like a trapezoidal pulse 
(Li et al., 2015). According to that the dynamic load multiplier was simulated as rectified sine wave (half a versine) haversine wave, its Eq. 1:

$$
y=\sin ^{2}(\omega t)
$$

Where:

$\mathrm{y}=$ Wave multiplier

$\omega=$ Circular frequency $(\mathrm{rad} / \mathrm{sec})$

$\mathrm{t}=$ Dynamic time $(\mathrm{sec})$

For this type of wave:

Where:

$$
\omega \mathrm{T}=\mathrm{Tf} \pi
$$

$\mathrm{T}=$ The wave time period

$\mathrm{f}=1 / \mathrm{T}=\omega / \pi \rightarrow \omega=\mathrm{f} \pi$

$\mathrm{f}=$ Load frequency $(\mathrm{Hz})$

\section{RESULTS AND DISCUSSION}

The full scale model is investigated using a parametric analysis. Since, the purpose of this analysis is to evaluate the fundamentals rather than quantitative results, only three design factors are investigated in this finite element analysis they are axle load amplitude, frequency (train speed) and the subgarde layer degree of saturation.

The load frequency is the main parameter that is investigated as its relate and reflect the train speed (the faster train speed means the higher load frequency) with two load amplitude values 200 and $250 \mathrm{kN}$ and three different degree of subgrade layer saturation 100,70 and $60 \%$.

Figure 4 and 5 are selected cases to demonstrate the of pressure and settlement and shape. They show the pressure and settlement contours of $250 \mathrm{kN}$ load

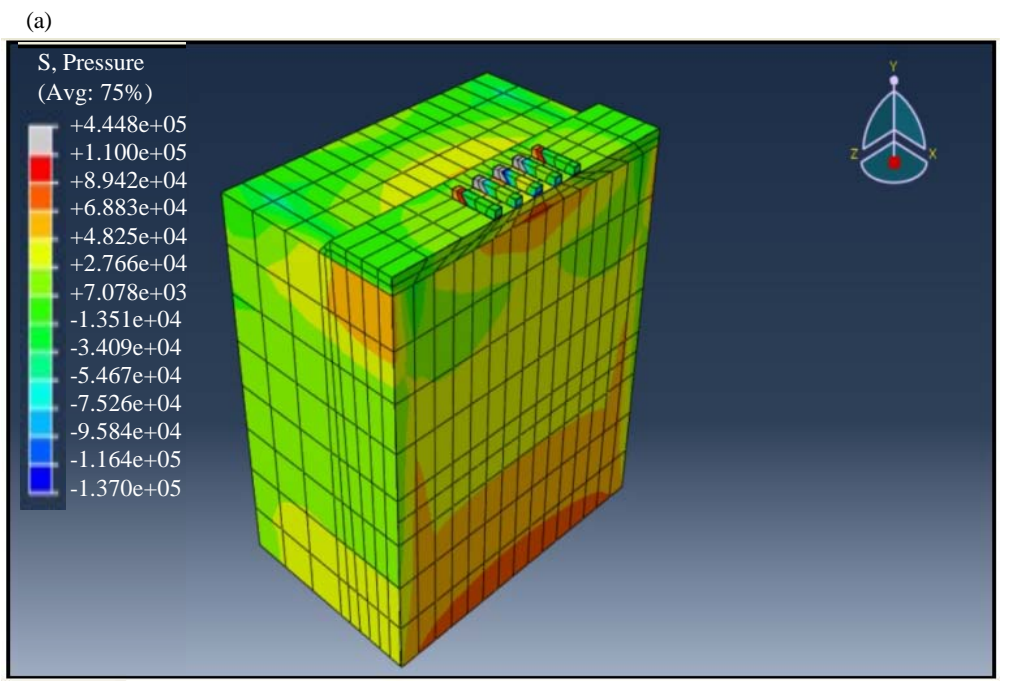

(b)

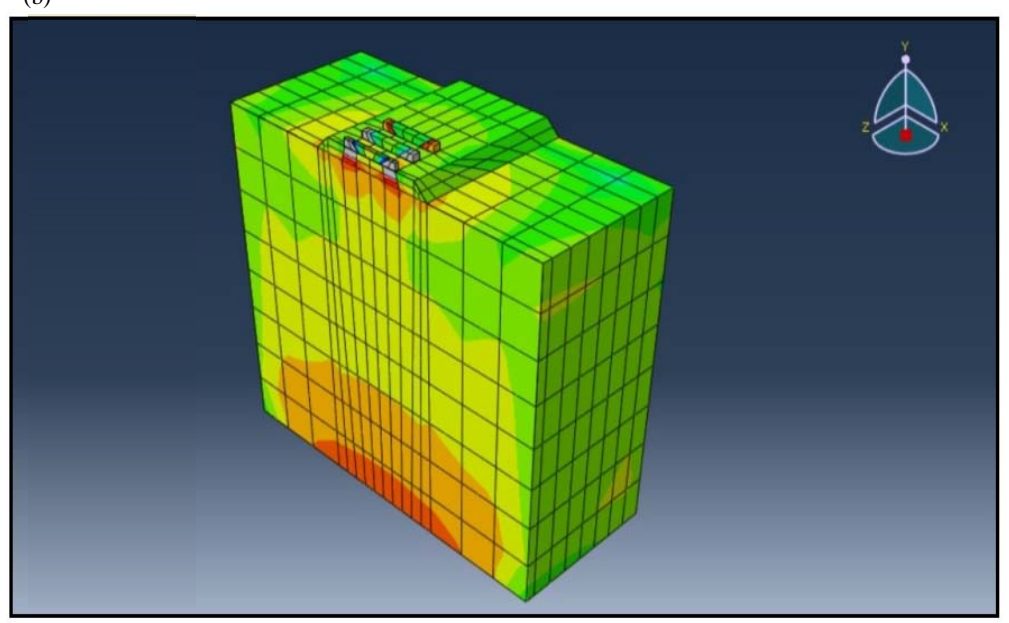

Fig. 4: Vertical pressure contours $(\mathrm{kPa})$ of $250 \mathrm{kN}$ load amplitude, $10 \mathrm{~Hz}$ frequency and $60 \%$ subgrade degree of saturation: a) Under middle sleeper and b) Under rail position 


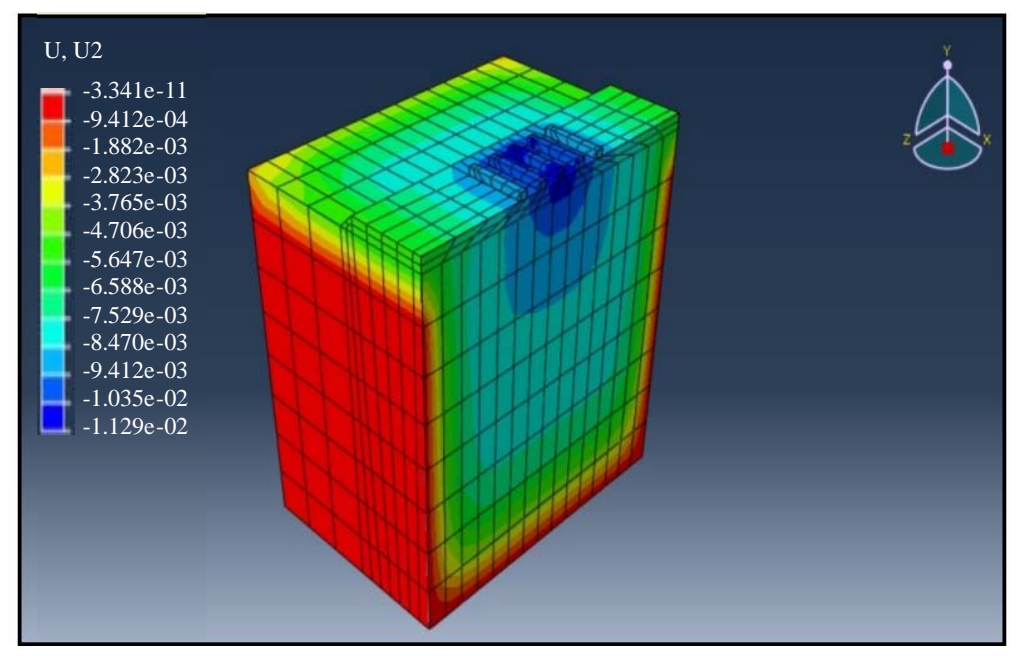

Fig. 5: Settlement contours (m) of $250 \mathrm{kN}$ load amplitude, $10 \mathrm{~Hz}$ frequency and $100 \%$ subgrade degree of saturation

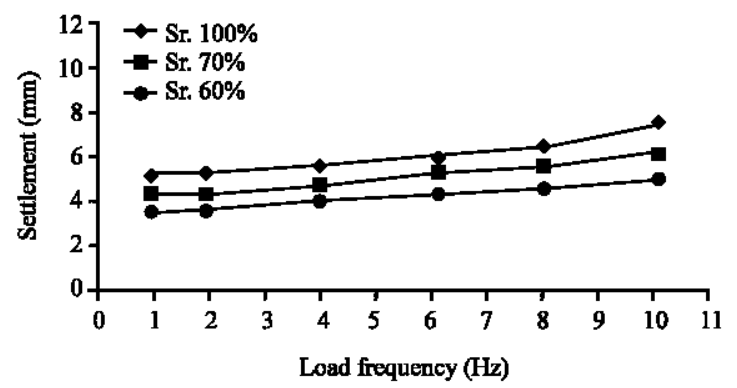

Fig. 6: Track rail settlement relation with load frequency at 100,70 and $60 \%$ degree of saturation under $200 \mathrm{kN}$ load amplitude

amplitude, $10 \mathrm{~Hz}$ frequency and subgrade degree of saturation of $60 \%$ for the pressure and $100 \%$ for the settlement.

Figure 6 and 7 show the relation between the load frequency and the track rail settlement at subgrade layer degree of saturation 60,70 and 100 under load amplitudes 200 and $250 \mathrm{kN}$, respectively. The track rail settlements are calculated by taking the average settlement of all the five sleepers.

It can be noted that at $100 \%$ subgrade degree of saturation and $200 \mathrm{kN}$ load amplitude, the increase of load frequency from $1-10 \mathrm{~Hz}$ leads to track rail settlement increase by $40 \%$. While for the same load amplitude and the same load frequency increase, the track rail settlement increases ratio was 43 and $40 \%$ at subgrade layer degrees of saturation 70 and 60 , respectively as illustrated in 6 .

Figure 7 shows that under load amplitude $250 \mathrm{kN}$, the increase of load frequency from 1-10 resulted in increase in track rail settlement by $38 \%$ for $100 \%$ subgrade degree of saturation and by $40 \%$ in case of $70 \%$ degree of saturation and $43 \%$ for $60 \%$ degree of saturation.

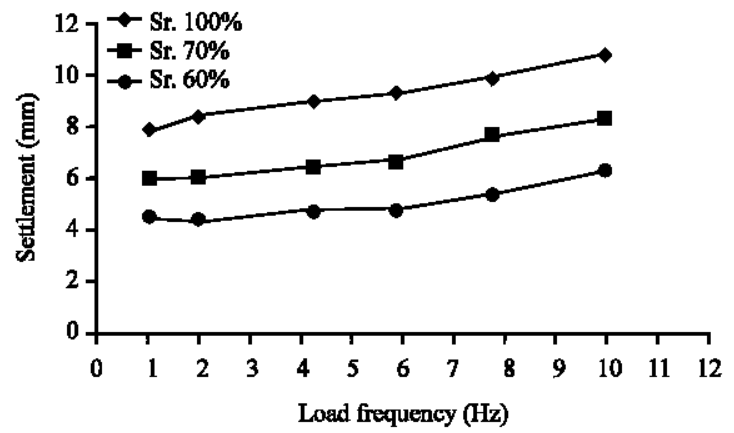

Fig. 7: Track rail settlement relation with load frequency at 100,70 and $60 \%$ degree of saturation under $250 \mathrm{kN}$ load amplitude

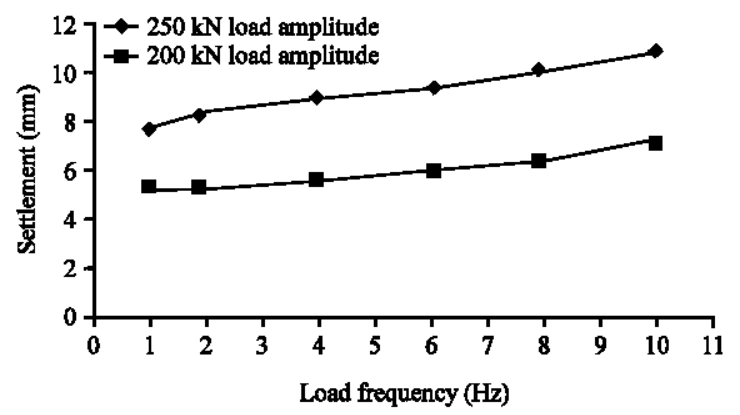

Fig. 8: Track rail settlement relation with load frequency at $100 \%$ degree of saturation under 200 and $250 \mathrm{kN}$ load amplitude

Figure 8-10 are drawn for the relation of load frequency effect and settlement of the track rail for a single degree of saturation and at load amplitude 200 and 250 . Figure 8-10 show that the increase of track rail 


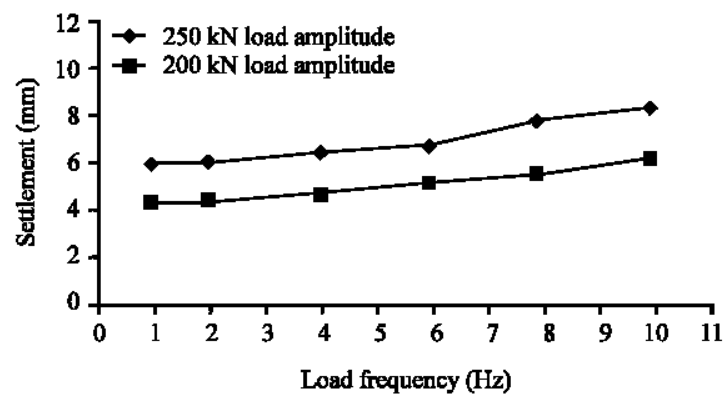

Fig. 9: Track rail settlement with load frequency at $70 \%$ degree of saturation under 200 and $250 \mathrm{kN}$ load amplitude

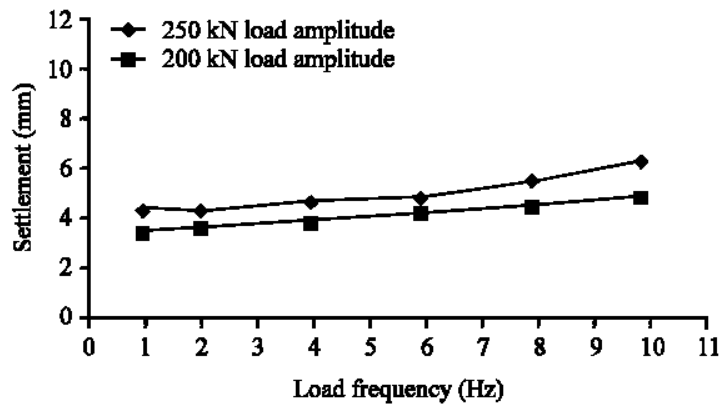

Fig. 10: Track rail settlement with load frequency at $60 \%$ degree of saturation under 200 and $250 \mathrm{kN}$ load amplitude

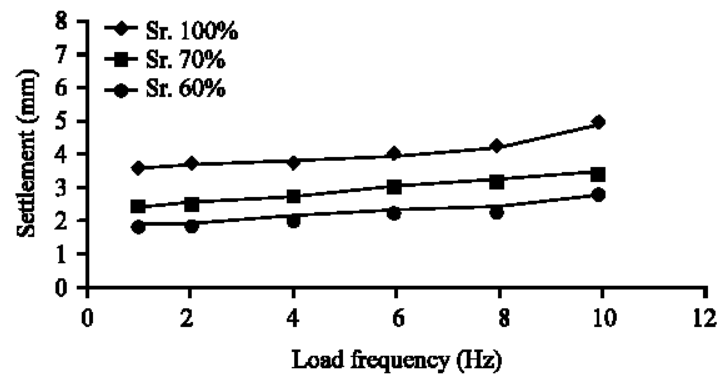

Fig. 11: Subgrade settlement relation with load frequency at $100 \%$ degree of saturation under 200 and $250 \mathrm{kN}$ load amplitude

settlement as a result of load frequency increasing ranges from $0.38-43 \%$. The results clearly indicate that the increase of load frequency from 1-10 Hz led to close values of increasing in the rate of the track rail settlement at all cases of degrees of saturation and load amplitudes.

Figure 11 and 12 present the settlement of the subgrade layer at various load frequencies and at subgarade degree of saturation 100,70 and $60 \%$ under

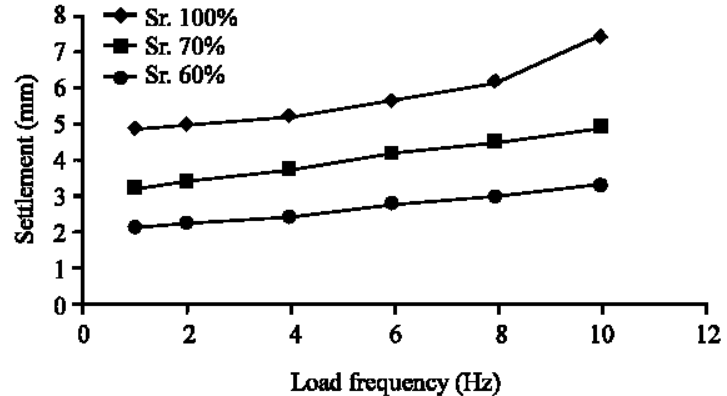

Fig. 12: Track rail settlement with load frequency at $100 \%$ degree of saturation under 200 and $250 \mathrm{kN}$ load amplitude

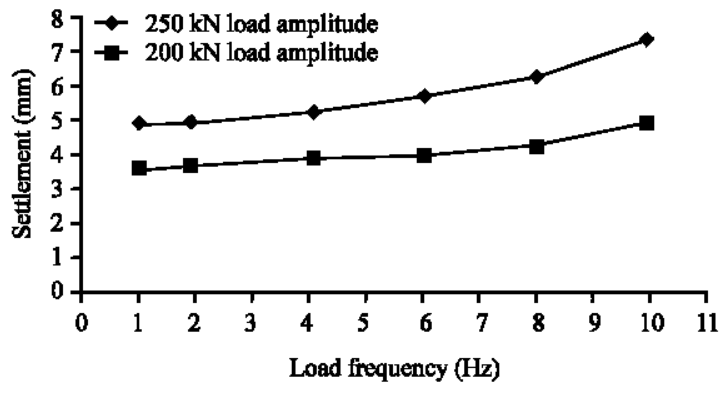

Fig. 13: Relationship between load frequency with subgrade settlement at $100 \%$ degree of saturation under 200 and $250 \mathrm{kN}$ load amplitude

load amplitude 200 and $250 \mathrm{kN}$, respectively. The subgrade settlement represents the average settlement beneath the sleepers at the subgrade layer surface.

The results presented in these two figures of the subgrade settlement illustrate that under load amplitude $200 \mathrm{kN}$, the increase of the subgrage settlement when the load frequency increased from 1-10 was about 36, 41 and $46 \%$ at subgrade degree of saturation 100,70 and $60 \%$, respectively.

In case of load amplitude $250 \mathrm{kN}$, it can be noted that when the load frequency increased from 1-10, the subgrade settlement was increased about 52,53 and $57 \%$ at subgrade degree of saturation 100,70 and $60 \%$.

Figure 13-15 are drawn for the subgrade settlement with the load frequency at single saturation degree of the subgrade layer and load amplitude of 200 and $250 \mathrm{kN}$. The increase of frequency at $100 \%$ subgrade saturation from $1-10 \mathrm{~Hz}$ resulted in 36 and $52 \%$ increase for 200 and $250 \mathrm{kN}$ load amplitude, respectively. In case of subgrade saturation $70 \%$, the increase of subgrade settlement was $41 \%$ for $200 \mathrm{kN}$ and $53 \%$ for $250 \mathrm{kN}$ load amplitude. While in case of $60 \%$ subgrade saturation, the increasing of frequency from 1-10 led to increasing in the settlement of the subgrade by $46 \%$ for $200 \mathrm{kN}$ and by $57 \%$ for $250 \mathrm{kN}$ load amplitude. 


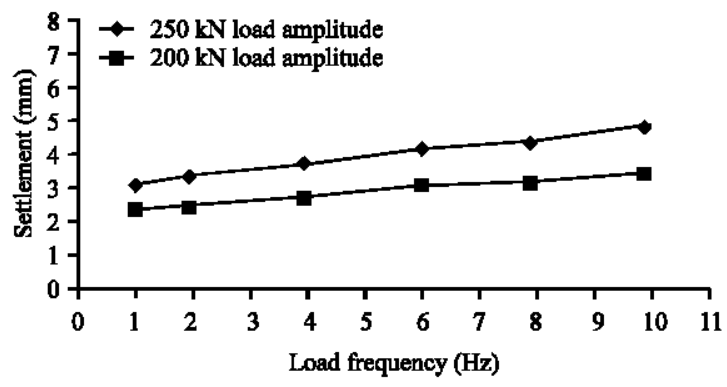

Fig. 14: Relationship between load frequency with subgrade settlement at $70 \%$ degree of saturation under 200 and $250 \mathrm{kN}$ load amplitude

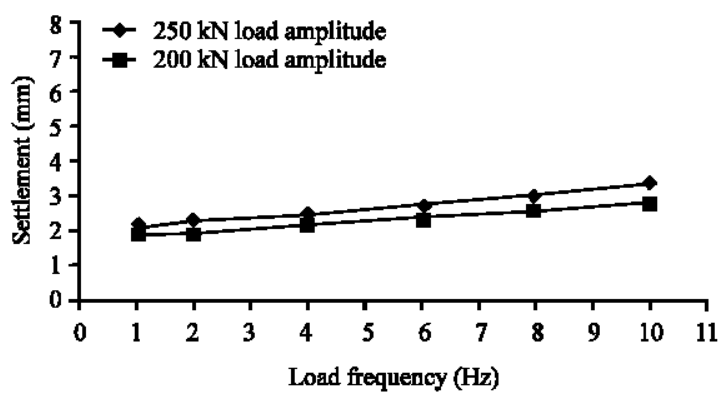

Fig. 15: Relationship between load frequency with subgrade settlement at $70 \%$ degree of saturation under 200 and $250 \mathrm{kN}$ load amplitude

The results show that the increases of load frequency has a higher impact on subgrade settlement at the higher load amplitude and the lower degree of saturation.

The results also show that the effect of load amplitude on the track rail and subgrade settlement is higher for the subgrade layers having higher degree of saturation.

The increases of load amplitude give almost the same track rail settlement increases ration for both 1 and $10 \mathrm{~Hz}$ load frequency in case of subgrade degree of saturation $100 \%$. The same result is observed at 70 and $60 \%$ subgrade degree of saturation.

For the subgrade settlement, the increases of load amplitude from 200-250 kN in case of subgrade degree of saturation $100 \%$ result in a subgrade settlement increases ratio of $35 \%$ for $1 \mathrm{~Hz}$ and $50 \%$ at $10 \mathrm{~Hz}$ load frequency. At $70 \%$ degree of saturation, the increase of load amplitude from 200-250 kN leads to increase of settlement about 31 and $42 \%$ for the frequency 1 and $10 \mathrm{~Hz}$, respectively. While in case of $60 \%$ degree of saturation when load amplitude increases from $200-250 \mathrm{kN}$, the increase of settlement is about 9 and $17 \%$ for the frequency 1 and 10 $\mathrm{Hz}$, respectively. These results clearly indicate that the increase of load amplitude has higher effect on subgrade settlement at higher load frequency.
As a result, it can be concluded that the reduction of the subgrade degree of saturation results in decrease in both track rail and subgrade settlement and the percentage of this reduction is not effaced by the load frequency value. For example when the subgrade saturation was reduced from $100-60 \%$ under load amplitude $200 \mathrm{kN}$ for frequency 1 and $10 \mathrm{~Hz}$, the reduction in track rail was about $32 \%$ for both frequency magnitude. The reduction of the subgrade degree of saturation has a higher effect on the both the track rail and the subgrade settlement at higher load amplitude.

Randeniya et al. (2016) conducted finite element analysis on unsaturated soil by Abaqus/Explicit, the results indicated that according to the effect of water, meniscus between the soil particles creates an additional normal force due to suction, this leads to making the soil stiffer with less susceptible to deformation and such effect makes the soil absorb more energy induced by traffic loads.

When a subgrade layer becomes unsaturated, an air-water interface generated in each void as a result of voids are partly filled with water and partly occupied by air when the degree of saturation of the subgard layer decrease, there will be a matric suction increasing that led to the radius of an air-water interface decreases, result in inducing a larger normal interparticle contact force (Mancuso et al., 2002; Wheeler et al., 2003; Ng and Yung 2008). This normal interparticle contact force gives a improving effect on an unsaturated soil by restraining slippage at particle contacts and reinforcing the shear resistance of the unsaturated soil (Wheeler et al., 2003).

The higher the load capacity amplitude, the more saturation reduction effect on the settlement decreases. This can be seen in case of reducing the subgrade degree of saturation from $100-60 \%$ which led to reduction in track rail settlement by $32 \%$ for $200 \mathrm{kN}$ and about $41 \%$ for the $250 \mathrm{kN}$ load amplitude.

\section{CONCLUSION}

The increase of load frequency leads to increase in rate of track rail and this rate of increases was almost same for all degrees of saturation. The increase of load frequency leads to increase in rate of subgrade settlement and this rate of increase is higher at the higher load amplitude and the lower degree of saturation. At the same load frequency value, the increasing of load amplitude results in higher rate of subgrade and track rail settlement increases for the case of higher subgrade degree of saturation than lower one.

The increase of track rail settlement ratio regarding to load amplitude increases is independent on load frequency value. While for the subgrade settlement, the 
increase of load amplitude gives higher value of settlement increase ratio when the load frequency is higher.

The reduction of the subgrade degree of saturation resulted in decrease in both track rail and subgrade settlement and the percentage of this reduction is not effaced by the load frequency value. On the other hand, the reduction of the subgrade degree of saturation has a higher effect on the both the track rail and the subgrade settlement at higher load amplitude.

\section{REFERENCES}

Anonymous, 2011. Engineering (Track \& Civil) code of practice, section 0.track and civil management system. Australian Rail Track Corporation LTD (ARTC), Mile End, Australia.

Awoleye, E.O.A., 1993. Ballast type-ballast life predictions. Master Thesis, LR Health \& Beauty Systems, London, Engaland, UK.

Chandra, S. and M.M. Agarwal, 2007. Railway Engineering. Oxford University Press, India, ISBN-13: 9780195687798, Pages: 590.

Esveld, C., 2001. Modern Railway Track. 2nd Edn., Mass Rapid Transit, Chennai, India, ISBN:9789080032439, Pages: 654.

Fattah, M.Y., M.R. Mahmood and M.F. Aswad, 2017. Experimental and numerical behavior of railway track over geogrid reinforced ballast underlain by soft clay. Proceedings of the 2017 International Congress and Exhibition on Sustainable Civil Infrastructures: Innovative Infrastructure Geotechnology, July 15-19, 2017, Springer, Berlin, Germany, ISBN:978-3-319-61626-1, pp: 1-26.

Francois, B. and L. Laloui, 2008. ACMEG-TS: A constitutive model for unsaturated soils under non-isothermal conditions. Intl. J. Numer. Anal. Methods Geomech., 32: 1955-1988.

Grabe, P.J., 2003. Resilient and permanent deformation of railway foundations under principal stress rotation. $\mathrm{PhD}$ Thesis, University of Southampton, Southampton, England.

Jin, M.S., K.W. Lee and W.D. Kovacs, 1994. Seasonal variation of resilient modulus of subgrade soils. J. Transp. Eng., 120: 603-616.

Khoury, N. and M. Zaman, 2004. Correlation between resilient modulus, moisture variation and soil suction for subgrade soils. J. Transp. Res. Board, 1874: 99-107.

Leshchinsky, B. and H.I. Ling, 2013. Numerical modeling of behavior of railway ballasted structure with geocell confinement. Geotext. Geomembr., 36: 33-43.
Li, D., 1994. Railway track granular layer thickness design based on subgrade performance under repeated loading. Ph.D Thesis, Department of Civil Engineering, University of Massachusetts, Amherst, Boston.

Li, D., T. Sussmann, J. Hyslip and S. Chrismer, 2015. Railway Geotechnics. Taylor and Francis, Milton Park, Didcot, ISBN:9780415695015, Pages: 584.

Mancuso, C., R. Vassallo and A. d'Onofrio, 2002. Small strain behavior of a silty sand in controlled-suction resonant column torsional shear tests. Can. Geotech. J., 39: 22-31.

McCartney, J.S. and A. Khosravi, 2012. Field-monitoring system for suction and temperature profiles under pavements. J. Perform. Constr. Facil., 27: 818-825.

Ng, C.W.W. and S.Y. Yung, 2008. Determination of the anisotropic shear stiffness of an unsaturated decomposed soil. Geotechnique, 58: 23-35.

Nieto-Leal, A. and V. Kaliakin, 2013. Behavior of cohesive soils subjected to cyclic loading: An extensive review of pertinent literature. Master Thesis, Department of Civil and Environmental Engineering, University of Delaware, Newark, Delaware, USA.

Otter, L., 2011. The influence of suction changes on the stiffness of railway formation. Ph.D Thesis, University of Southampton, Southampton, England.

Profillidis, V.A., 2000. Railway Engineering. Ashgate Publishing Limited, Farnham, UK.,

Randeniya, C., D. Robert and C. Li, 2016. The effect of traffic loading to buried water mains in partially saturated soils. Proceedings of the 6th International Conference on Asia Pacific Unsaturated Soils: Unsaturated Soil Mechanics-from Theory to Practice (AP-UNSAT 2015), October 23-26, 2015, CRC Press, Guilin, China, ISBN:9781138029217, pp: 883-888.

Romero, E., A. Gens and A. Lloret, 2003. Suction effects on a compacted clay under non-isothermal conditions. Geotechnique, 53: 65-81.

Selig, E.T. and J.M. Waters, 1994. Track Geotechnology and Substructure Management. Thomas Telford, London, England, UK., ISBN:9780727720139,

Tang, A.M., Y.J. Cui and N. Barnel, 2008. Thermo-mechanical behaviour of a compacted swelling clay. Classical Phys., 58: 45-54.

Uchaipichat, A. and N. Khalili, 2009. Experimental investigation of thermo-hydro-mechanical behaviour of an unsaturated silt. Geotechnique, 59: 339-353.

Vanapalli, S.K., W.S. Sillers and M.D. Fredlund, 1998. The meaning and relevance of residual state to unsaturated soils. Proceedings of the 51st Canadian Geotechnical Conference, (CGC'98), Edmonton, pp: 101-108.

Wheeler, S.J., R.S. Sharma and M.S.R. Buisson, 2003. Coupling of hydraulic hysteresis and stress-strain behaviour in unsaturated soils. Geotechnique, 53: 41-54. 